\title{
Stay Out of Bed
}

National Cancer Institute

\section{Source}

National Cancer Institute. Stay Out of Bed. NCI Thesaurus. Code C95543.

The ability to maintain the energy required to be out of bed. 